\title{
Partnerships Among Canadian Agencies Serving Women with Substance Abuse Issues and Their Children
}

\author{
Wendy Sword • Alison Niccols • Reza Yousefi-Nooraie • \\ Maureen Dobbins • Ellen Lipman • Patrick Smith
}

Published online: 9 January 2013

C The Author(s) 2013. This article is published with open access at Springerlink.com

\begin{abstract}
Women with substance use issues and their children have unique needs that are best met through collaborative and coordinated service delivery offered by a variety of agencies. However, in Canada and elsewhere, services tend to be fragmented and fail to address children's needs. This study aimed to describe the partnership patterns, activities, and qualities among Canadian agencies serving women with addictions and to determine predictors of partnerships. We found that a number of partnerships exist, and that the extent and characteristics of these partnerships vary. Agency responsiveness to clients was predictive of sending referrals whereas friendliness predicted joint programming and consultation. Four central agencies played key linkage roles. Efforts should be made to build on the social capital inherent in these agencies to strengthen existing networks, further develop linkages to improve service delivery, and promote evidence-informed practice in a field where there is an identified research-practice gap.
\end{abstract}

Keywords Substance abuse $\cdot$ Women $\cdot$ Agency partnerships $\cdot$ Service collaboration $\cdot$ Social network analysis

W. Sword $(\square) \cdot$ M. Dobbins

School of Nursing and Department of Clinical Epidemiology and Biostatistics, McMaster University, HSC 3H48B, 1280 Main Street West, Hamilton, Canada L8S 4K1

e-mail: sword@mcmaster.ca

A. Niccols

Hamilton Health Sciences and Department of Psychiatry and Behavioural Neurosciences,

McMaster University, Hamilton, Canada

R. Yousefi-Nooraie

Health Research Methodology Program, McMaster University, Hamilton, Canada

E. Lipman

Department of Psychiatry and Behavioural Neurosciences,

McMaster University and Offord Centre for Child Studies, Hamilton, Canada

P. Smith

Renascent, Toronto, Canada and Department of Psychiatry, University of British Columbia, Vancouver, Canada 


\section{Background}

It is widely acknowledged that " $[\mathrm{t}]$ he use of substances is associated with negative social, public safety and economic consequences for all Canadians" (Health Canada 2012, para. 1). Substance abuse (alcohol or illicit drugs) puts women at increased risk for a wide-range of related health and social problems and it can significantly impact both women's and children's well-being during pregnancy and after childbirth (Kelley 1998; Poole and Dell 2005). Substance abuse is associated with maternal, fetal, and neonatal morbidity, prematurity, and small for gestational age (Goel et al. 2011; Kuczkowski 2007; Schempf 2007). Women who abuse substances experience parenting deficits that are related, in part, to co-occurring psychological and environmental concerns (Mayes and Truman 2002; Suchman and Luthar 2000). This constellation of factors puts their children at risk for abuse and neglect (Dunn et al. 2002; Walsh et al. 2003). Children of parents with substance abuse issues can experience a wide range of physical, psychological, behavioural, emotional, and academic problems (Conners et al. 2004). Given the numerous challenges for women who abuse substances, they have unique service needs that current treatment models often overlook, thereby creating barriers to accessing services. At a systems level, barriers include narrowly defined service mandates, fragmented care, and lack of attention to and support for the mother-child unit (Poole and Urquhart 2010).

In response to these issues, there has been growing interest in coordinated and integrated services for women who abuse substances that support them in their parenting roles. It is recognized that addiction treatment needs to address the full range of women's needs to be effective (Center for Substance Abuse Treatment 2009) and, as noted in a United Nations report, "Engaging and retaining pregnant and parenting women in treatment requires collaboration between the substance abuse treatment sectors of prenatal care and child welfare. ... Ideally, services should be accessed through a single site" (p. 3). The research evidence suggests that integrated programs are effective in reducing maternal substance use, improving maternal mental health, fostering use of prenatal care and favourable birth outcomes, and enhancing parenting skills (Milligan et al. 2010, 2011; Niccols et al. 2010, 2012). Additionally, women report that participation in an integrated program contributes to maternal well-being, a sense of personal agency, the establishment of positive social support networks, greater insight into and capacity for relationships, and improved maternal-child communication (Sword et al. 2009).

Integrated programs are founded on the coordination of addiction programs with other services and agencies. A beginning step is the establishment of collaborative relationships with community partners in allied services to create cross-sectoral linkages. By working together, service providers are able to address complex health and social problems and meet a broad range of needs (Provan et al. 2005). Additionally, collaborative relationships can allow for more efficient use of limited resources and improve the effectiveness of services offered (Provan et al.). As Provan and colleagues commented, "In many communities organizational networks have become an important mechanism for ... systematically planning for how [complex health and social] problems might best be addressed, and delivering needed services" (p. 603).

Cross-sector linkages or networks also create a vehicle for information exchange and thus can play a role in fostering new practices (Greenhalgh et al. 2004), ideally those that are informed by research evidence. Although there have been numerous advances in the treatment of addictions, there is a widely-recognized gap between practice in treatment settings and research evidence (Damschroder and Hagedorn 2011; Garner 2009; Miller et al. 2006; Roman et al. 2010). Improvements in dissemination and knowledge translation therefore have been recommended (Damschroder \& Hagedorn). The use of networks for 
the promotion of evidence-informed practice is proposed in Canada's National Treatment Strategy (National Treatment Strategy Working Group 2008) and is supported by Rogers' (2003) diffusion of innovation theory, which explains how new ideas and practices spread through formal or informal communication channels and linkages. Research findings support the effectiveness of inter-organizational networks in exposing organizational leaders to information about evidence-informed practices and in influencing decisions to adopt such practices (Palinkas et al. 2011). Moreover, agency collaboration can be critical to the implementation of evidence-informed practices because single agencies often lack the resources to implement the practices independently (Palinkas et al.).

In response to the need to decrease the gap between research evidence and practice, specifically as it relates to women with substance abuse issues and their children in Canada, we brought together a group of researchers, clinicians, program managers, executive directors, and policy makers, with the main objective of developing and evaluating a knowledge translation and exchange strategy to foster evidence-informed practices and, ultimately, improve services for this population. Through our work we also aimed to foster relationships between agencies offering treatment services for women with addictions and other agencies that serve women and their children to encourage and promote collaborative service delivery and the sharing of knowledge to inform practices. As part of our program of research, we conducted an initial survey of staff in agencies across Canada with addiction treatment services for women. As part of this survey we collected data on the program manageridentified community partners of these agencies for the purposes of being able to: (1) describe existing partnership patterns among agencies in Canada serving women with addictions; (2) describe the partnership activities and qualities of the partnerships among agencies in Canada serving women with addictions; and (3) determine the predictors of agency partnerships. These data would not only provide information about existing networks but also provide direction for further development of collaborative partnerships.

\section{Methods}

\section{Sample and Recruitment}

An invitation to participate in an online survey was sent by email to staff (executive directors, program managers, and clinicians) at agencies across Canada that provide addiction treatment services for women. The agency list was obtained from the National Directory of Drug and Alcohol Abuse Treatment compiled by the Canadian Centre for Substance Abuse. Agencies were contacted to confirm that they provided substance abuse services for women and to obtain contact information for their executive directors (or equivalent). Up to five email reminders were sent to non-respondents. The invitation included a link to the survey and participants were asked to endorse a consent that addressed issues of confidentiality and rights as a study participant. Participants received a \$25 gift certificate and the option of having their name entered into a draw for a trip to a national addictions conference. Ethics approval for the study was received from the Hamilton Health Sciences/McMaster University Faculty of Health Sciences Research Ethics Board.

\section{Data Collection}

The survey was administered online. All respondents answered questions about their use of research evidence; program managers were asked to complete additional questions related to 
their agency's community partners and the nature of the relationship with each self-identified partner. Respondents were able to list up to six key community partners with which their program had a relationship and to indicate the type of activities that occurred, i.e., referrals sent, referrals received, information shared, joint programming, consultation. In addition, they were asked to rate both the overall quality of their agency's relationship with each partner and specific qualities of the relationship (responsiveness to their clients, responsiveness to their staff, trust, friendliness, and productivity) using a 5-point scale (very poor, poor, undecided, good, very good). Up to five reminders to complete the survey were emailed to agency staff.

\section{Data Analysis}

The responding agencies were categorized into four main groups: addictions (substance abuse treatment); adult mental health; health care (primary care, public health, women's health, hospital); and social (immigrant/cultural/justice, municipal/housing, charity, religious). Partner agencies were categorized into these same four plus an additional three groups: prenatal/postnatal (prenatal clinics, pregnancy/parenting support groups, programs for pregnant women); child (childcare, child development, child protection, children's mental health, early childhood and early learning, parenting); and university. Although not directly involved in the provision of services to women with substance abuse issues, universities were identified as community partners given the role of community-university partnerships in promoting evidence-informed practice (Dulmus and Cristalli 2012). As such, we did not expect universities to play a role in any of the identified activities except consultation.

Descriptive statistics were used to summarize the characteristics of study participants, expressed as number (percent) for categorical variables and mean and standard deviation (SD) for continuous variables. We depicted the partnership information in the form of a graphical map representing the inter-organizational partnership network, using Gephi software (Bastian et al. 2009). In the network map, each node represents an agency, and each line connecting pairs of agencies represents the partnership between them. The size of the nodes in the map is proportional to the number of partnerships in which those nodes are involved. In other words, more popular agencies are shown by bigger circles. With this analysis, we were able to examine the connections and relationships between pairs of agencies (dyads), among clusters of agencies, and among all of the agencies encompassed by the network (Provan et al. 2005). In order to assess the association between various partnership types and qualities of relationships, we conducted a two-level logistic regression with random intercept. The first level consisted of respondent-partner pairs, and the second level consisted of the responding agencies (because respondents from each agency identified more than one partner). The odds ratios (and standard errors) for the occurrence of each partnership type by one unit increase in the scores for various aspects of the quality of relationship were calculated.

\section{Results}

Of 750 programs in 526 agencies invited to participate, 363 programs (48\%) in 270 agencies $(51 \%)$ agreed to take part in the survey; $12 \%$ of agencies refused participation and $37 \%$ did not respond. The number of invited agencies and response rates by province and territory are shown in Table 1. A total of 222 program managers from 106 agencies 
Table 1 Response rates by province and territory $(n=526)$

\begin{tabular}{lcc}
\hline Province/Territory & $\begin{array}{c}\text { Invited } \\
\text { Agencies } n\end{array}$ & $\begin{array}{c}\text { Respondent } \\
\text { Agencies } n(\%)\end{array}$ \\
\hline British Columbia & 155 & $26(17)$ \\
Yukon & 8 & $1(13)$ \\
Alberta & 38 & $9(24)$ \\
Northwest Territories & 8 & $1(13)$ \\
Nunavet & 2 & $0(0)$ \\
Saskatchewan & 25 & $2(8)$ \\
Manitoba & 14 & $5(36)$ \\
Ontario & 185 & $53(29)$ \\
Quebec & 59 & $2(3)$ \\
New Brunswick & 10 & $3(30)$ \\
Nova Scotia & 11 & $1(9)$ \\
Prince Edward Island & 4 & $2(50)$ \\
Newfoundland & 7 & $1(14)$ \\
\hline
\end{tabular}

responded to the portion of the survey assessing partnerships, thereby representing $39 \%$ of the 270 participating agencies and $20 \%$ of the 526 invited agencies. The characteristics of study participants are presented in Table 2 . Half $(50 \%)$ of the agencies in which the respondents were employed were located in Ontario $(n=53), 25 \%$ in British Columbia $(n=26), 8 \%$ in Alberta $(n=9), 5 \%$ in Manitoba $(n=5), 3 \%$ in New Brunswick $(n=3)$, and $9 \%(n=10)$ in other provinces. The 222 respondents from the 106 agencies identified 1134 community partners.

\section{Partnership Patterns}

The frequencies of partnerships between the different agency categories are shown in Table 3. The table should be interpreted row-wise because most of the partners were not included or did not participate in the survey, consequently their partnership patterns are not

Table 2 Characteristics of survey respondents $(n=222)$

\begin{tabular}{lc}
\hline Characteristic & $n(\%)$ \\
\hline Highest level of education & $11(5.0)$ \\
High school & $55(24.7)$ \\
College diploma & $155(69.8)$ \\
Any university & $1(0.5)$ \\
Other & $49(22.1)$ \\
Years in current position & $55(24.8)$ \\
$<2$ & $118(53.1)$ \\
$2-5$ & $13(5.8)$ \\
$>5$ & $33(14.9)$ \\
Years experience working in addictions & $176(79.3)$ \\
$<2$ & \\
$2-5$ & \\
$>5$ & \\
\hline
\end{tabular}


Table 3 The frequencies of partnership among different agency categories

\begin{tabular}{|c|c|c|c|c|c|c|c|}
\hline $\begin{array}{l}\text { Partners } \\
\text { Respondents }\end{array}$ & $\begin{array}{l}\text { Addictions } \\
n(\%)\end{array}$ & $\begin{array}{l}\text { Adult mental } \\
\text { health } n(\%)\end{array}$ & $\begin{array}{l}\text { Health } \\
\text { care } n(\%)\end{array}$ & $\begin{array}{l}\text { Prenatal/ } \\
\text { postnatal } \\
n(\%)\end{array}$ & $\begin{array}{l}\text { Child } \\
n(\%)\end{array}$ & $\begin{array}{l}\text { Social } \\
n(\%)\end{array}$ & $\begin{array}{l}\text { University } \\
n(\%)\end{array}$ \\
\hline Addictions $(n=62)$ & $4(66)$ & $34(55)$ & $42(68)$ & $5(8)$ & $37(60)$ & $55(89)$ & 12 (19) \\
\hline $\begin{array}{l}\text { Adult mental health } \\
\qquad(n=1)\end{array}$ & $1(100)$ & 0 & $1(100)$ & 0 & $1(100)$ & 0 & 0 \\
\hline Health care $(n=17)$ & $9(53)$ & $11(65)$ & $14(82)$ & $2(12)$ & $15(88)$ & $17(100)$ & $3(18)$ \\
\hline Social $(n=26)$ & $11(42)$ & $1(38)$ & $19(73)$ & $4(15)$ & $16(62)$ & $23(88)$ & $4(15)$ \\
\hline Total $(n=106)$ & $62(58)$ & $55(52)$ & $76(72)$ & $11(10)$ & $69(65)$ & $95(90)$ & $19(18)$ \\
\hline
\end{tabular}

known. The responding agencies most frequently partnered with social agencies, followed by health care and child agencies; they least frequently partnered with prenatal/postnatal services and universities.

The partnership network (Fig. 1) included 117 enlisted agencies; 62 participated in the survey and the rest were identified by survey respondents. Out of 106 responding agencies, 44 did not identify any enlisted agencies as their partners and were not themselves identified by any agency. These 44 agencies shaped the isolate nodes in the partnership network. In the network map, the nodes are sized according to their 'degree centrality', i.e., the number of links on each node. All partnership connections were among agencies within the same province. The network consisted of several small, mostly isolated clusters and three large clusters, two of which were centred around a large agency (Agency A and Agency B) and the other centred around one large and one smaller agency (Agency $\mathrm{C}$ and Agency D), which were indirectly connected. Agency A is responsible for a range of facilities, programs, and services in a regional setting whereas Agency B is responsible for a range of facilities, programs, and services at a provincial level. Agency $\mathrm{C}$ is a specialized hospital and research centre that provides a variety of services and Agency D is a treatment centre located in the same city as Agency C.

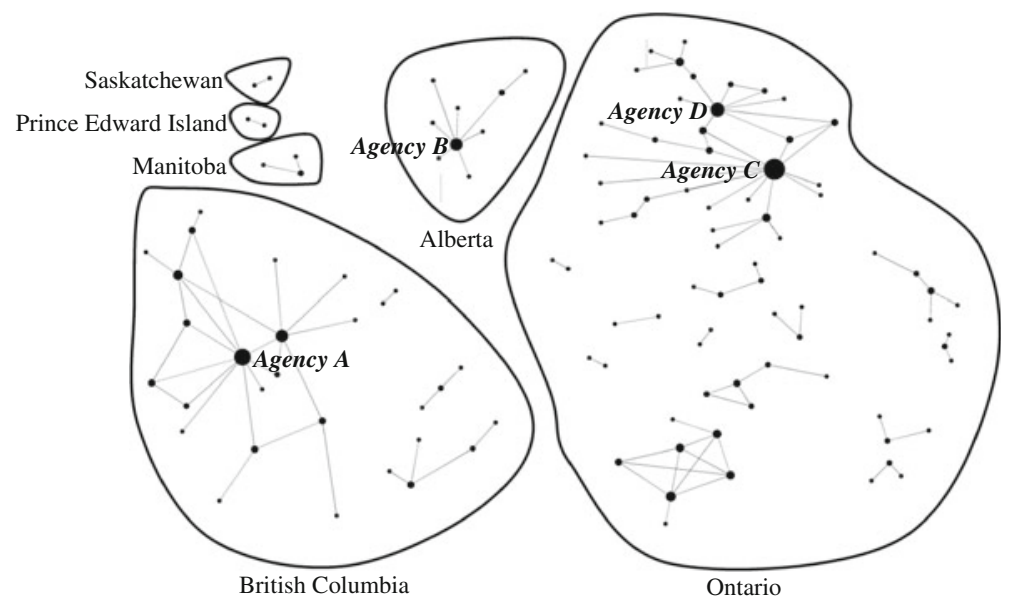

Fig. 1 The overall partnership connections network 
Respondents from Agency A identified 8 agencies, and were identified by 6 agencies as a partner, of which 4 were reciprocal connections. Of these, 3 were addictions agencies, 2 were health care agencies, and 5 were social agencies. Agency A was indirectly connected to 8 other agencies. Respondents from Agency B identified 5 agencies as partners, and themselves were identified by 4 agencies. Two connections were reciprocal, which resulted in 7 direct and 1 indirect partnership connections in the network. Of the direct partners 5 were addictions agencies, 1 was a social agency, and 1 was an adult mental health agency. Respondents from Agency $\mathrm{C}$ identified 8 other enlisted agencies, and 5 other agencies identified Agency $\mathrm{C}$ as a partner. Of these 13 agencies, 7 were addictions agencies, 5 were health care agencies, and one was a social agency. By connecting to these 13 agencies, Agency $\mathrm{C}$ was connected to 17 other agencies indirectly, which made it the most accessible agency in the network. It was followed by Agency D, which was directly connected to 8 and indirectly to 30 other agencies in the province.

\section{Partnership Activities and Qualities}

The degree to which different partnership activities co-occurred between respondent agencies and their self-identified community partners is shown in Table 4. Various partnership types (sending referrals, receiving referrals, information sharing, and consultation) often cooccurred. The exception was joint programming, which happened in only approximately $50 \%$ of the partnerships that involved other activities.

The overall quality of relationships with the 1134 identified community partners most often was rated as very good $(n=375 ; 33 \%)$ or good $(n=619 ; 55 \%)$. Similarly, specific qualities of the relationships also were generally rated as very good or good: responsiveness to clients $(n=938 ; 82.7 \%)$; responsiveness to staff $(n=963 ; 84.9 \%)$; trust ( $n=924 ; 81.5 \%)$; friendliness $(n=992 ; 87.5 \%)$; and productivity $(n=890 ; 78.4 \%)$.

\section{Predictors of Agency Partnerships}

Different partnership types were predicted by the overall relationship quality, specific relationship qualities, and by the type of community partner. The odds ratios for the occurrence of different partnerships are shown in Table 5. Respondent agencies were most likely to send referrals to adult mental health agencies, and were least likely to send referrals to child agencies and social agencies. Also, sending referrals was more likely if the partner agency was perceived as being responsive to clients whereas trust was a negative predictor of sending referrals. Respondent agencies were most likely to receive referrals from adult mental health and child agencies, and least likely to receive referrals from universities. Sharing of information was most likely to occur with health care agencies. Respondent agencies were most likely to receive referrals and share information if they perceived the

Table 4 Consensus among pairs of partnership types measured by the Jaccard's coefficient ( $n=106$ agencies, 1134 partnerships)

Referrals sent Referrals received Information shared Consultation Joint program

\begin{tabular}{lllll}
\hline Referrals sent & - & & & \\
Referrals received & 0.74 & - & & \\
Information shared & 0.71 & 0.80 & - & \\
Consultation & 0.62 & 0.71 & 0.77 & - \\
Joint programs & 0.43 & 0.50 & 0.53 & 0.59 \\
\hline
\end{tabular}


Table 5 Predictors of agency partnerships

\begin{tabular}{llllrr}
\hline & $\begin{array}{l}\text { Sent referrals } \\
\text { OR (SE) }\end{array}$ & $\begin{array}{l}\text { Received } \\
\text { referrals } \\
\text { OR (SE) }\end{array}$ & $\begin{array}{l}\text { Shared } \\
\text { information } \\
\text { OR (SE) }\end{array}$ & $\begin{array}{l}\text { Joint } \\
\text { programming } \\
\text { OR (SE) }\end{array}$ & $\begin{array}{l}\text { Consultation } \\
\text { OR (SE) }\end{array}$ \\
\hline Overall relationship quality & $1(0.2)$ & $1.5(0.3)^{\mathrm{c}}$ & $1.6(0.3)^{\mathrm{c}}$ & $2(0.3)^{\mathrm{a}}$ & $2.3(0.4)^{\mathrm{a}}$ \\
Responsiveness to clients & $3.3(0.6)^{\mathrm{a}}$ & $1(0.2)$ & $1(0.2)$ & $0.7(0.1)^{\mathrm{c}}$ & $0.7(0.1)^{\mathrm{c}}$ \\
Responsiveness to staff & $1.0(0.2)$ & $1(0.2)$ & $1.2(0.3)$ & $1.2(0.2)$ & $1.3(0.3)$ \\
Trust & $0.6(0.2)^{\mathrm{c}}$ & $1(0.3)$ & $0.7(0.2)$ & $1(0.2)$ & $0.8(0.2)$ \\
Friendliness & $0.8(0.2)$ & $0.6(0.2)$ & $1(0.3)$ & $2(0.4)^{\mathrm{b}}$ & $1.7(0.4)^{\mathrm{c}}$ \\
Productivity & $0.8(0.2)$ & $1.2(0.3)$ & $1(0.3)$ & $1(0.2)$ & $0.9(0.2)$ \\
Partner category: adult mental health & $3.6(2)^{\mathrm{b}}$ & $2.3(0.9)^{\mathrm{c}}$ & $1.3(0.5)$ & $1.6(0.4)$ & $1.2(0.4)$ \\
Partner category: health care & $1.2(0.4)$ & $1.5(0.5)$ & $2.3(1.0)^{\mathrm{c}}$ & $1.5(0.4)$ & $1.2(0.4)$ \\
Partner category: prenatal/postnatal & $2.5(3)$ & - & $0.5(0.4)$ & $0.5(0.4)$ & $1.2(1)$ \\
Partner category: child & $0.4(0.1)^{\mathrm{b}}$ & $2.2(0.8)^{\mathrm{c}}$ & $2(0.8)$ & $1.6(0.4)$ & $1.6(0.5)$ \\
Partner category: social & $0.4(0.1)^{\mathrm{b}}$ & $1.3(0.4)$ & $0.7(0.2)$ & $1.1(0.2)$ & $0.7(0.2)$ \\
Partner category: university & $0.1(0.07)^{\mathrm{a}}$ & $0.3(0.2)^{\mathrm{c}}$ & $0.8(0.5)$ & $1.4(0.7)$ & $0.5(0.3)$ \\
Constant (partner category: addiction) & $2.2(1.4)$ & $2.3(2)$ & $1.5(1)$ & $0.01(0.005)^{\mathrm{a}}$ & $0.09(0.06)^{\mathrm{a}}$ \\
\hline
\end{tabular}

Respondent agency was set as random level; addiction partner agency category was set as reference level

${ }^{\text {a }} p<0.001$

b $p<0.01$

${ }^{c} p<0.05$

overall quality of the interagency relationship as good. They were least likely to engage in joint programming or consultation with other addiction agencies. Joint programming and consultation were more likely to occur if the overall quality of the interagency relationship was good and the partner agency was perceived as friendly or as being responsive to clients.

\section{Discussion}

The findings of this study highlight existing relationships among agencies in Canada that provide addiction treatment for women and their community partner agencies from various service sectors. They also suggest that efforts should be made to strengthen and expand such partnerships to foster collaborative delivery of a range of services in order to meet the full spectrum of needs of women with substance abuse issues and their children.

Importantly, we found that the respondent addiction treatment agencies are most likely to send referrals to adult mental health, and to receive referrals from adult mental health or child agencies. The linkages with mental health services are essential given the association between addiction and serious mental illness (Epstein et al. 2004: Poole and Urquhart 2009). Moreover, most women with co-occurring problems of substance abuse and mental illness have a history of trauma, including childhood abuse, sexual abuse, and intimate partner violence (Poole \& Urquhart). The complexity of these issues and their potential impact on women and their children further underscores the need for adult mental health services. While some partnership activities occur between addiction treatment and mental health agencies, collaborative efforts can be further expanded, particularly to promote sharing of information and consultation. 
The receiving of referrals from child agencies also is noteworthy. However, child agencies were one of two types of agencies to which referrals were least likely to be sent. Partnerships with child welfare agencies are important because children of parents who abuse substances are at risk for abuse and neglect (Dunn et al. 2002; Walsh et al. 2003). The gap between child protection, one type of child agency, and substance abuse treatment services previously has been identified, with barriers to collaboration including diverse definitions of "client" (the child vs. the parent), differing attitudes toward parents who abuse substances, differences in policies and practices related to the expected timing of reunification efforts, and perceived costs of cross-sector collaboration (Drabble 2007). There also is a need to increase referrals to child-focused agencies that offer parenting services to enable mothers who abuse substances to enhance their parenting competence and to promote nurturing relationships with their children. Referrals to other kinds of child agencies (e.g., those focused on learning in early childhood) also can support children's healthy growth and development.

Social agencies, the other agency type to which referrals were least likely to be sent, are essential to the well-being of women and children because they play a vital role in ensuring that the social determinants of health are addressed. Research supports the need for education, including skill development and employment training, income-generation opportunities, safe housing, legal assistance, and social support among women with substance abuse issues (United Nations Office on Drugs and Crime 2004). "Historically, there has been little integration or effective communication within and between the systems and jurisdictions that provide services and supports to people with substance use problems" (National Treatment Strategy Working Group 2008, p. 1). Given that research evidence suggests that provision of integrated services across a broad range of sectors reduces substance abuse problems and also improves a wide range of outcomes related to health, social functioning, and criminal behaviour (National Treatment Strategy Working Group), it is imperative that efforts be made to expand inter-organizational linkages and collaboration across diverse service sectors (Howell and Chasnoff 1999).

Partnerships between agencies providing addiction treatment and prenatal/postnatal care agencies were relatively rare. Because substance abuse is associated with risk for significant maternal, fetal, and neonatal morbidity (Goel et al. 2011; Kuczkowski 2007; Schempf 2007), collaboration with prenatal services is essential to ensure that women who abuse substance receive timely and appropriate health care during their pregnancies. A meta-analysis found that compared to women who abuse substances who are not in treatment, women in integrated programs had more favourable birth outcomes; and compared to women in non-integrated programs, they attended more prenatal visits and had lower rates of preterm birth (Milligan et al. 2011). Pregnancy provides a window of opportunity as women often are motivated at this time to seek treatment for their addictions and to make behavioural changes out of concern for their unborn child (Chisolm and Coleman-Cowger 2011; Hjerkinn et al. 2007). Attention should be paid to the systems-level barriers to engagement in prenatal care among women with substance abuse issues. These barriers include public health messaging about the effects of substance use during pregnancy, which alarms some women to the point of delaying entry into prenatal care and contributes to the stigmatization of women such that they may be excluded from social networks that could facilitate prenatal care use (Roberts and Pies 2011). Additionally, the fact that some women fear being reported to child protection services suggests the need for a review and revision of reporting practices and policies (Roberts \& Pies).

The social network analysis revealed three large network clusters of agencies, each centred around one or two agencies located in the provincial capital. The four central 
agencies had several connections and exchanges with their surrounding agencies. This feature gives the agencies a significant superiority in terms of access to agencies and the capability of influencing a large number of partners. On the other hand, because the peripheral agencies in the clusters were mainly (and sometimes exclusively) connected to the central agencies, the likelihood of the formation of partnership among the peripheral agencies is limited. As such, the social capital inherent in the central agencies could be exercised to increase their accessibility and to expand the partnership networks of nearby agencies. Social capital has been defined as "the sum of the actual and potential resources embedded within, available through, and derived from the network of relationships possessed by an individual or social unit [agency]. Social capital thus comprises both the network and the assets that may be mobilized through that network" (Nahapiet and Ghoshal 1998, p. 243). This social capital ultimately could be leveraged to expand coordinated and collaborative service delivery for women with substance abuse issues and their children in Canada.

An important first step in promoting service delivery collaboration is ensuring that the involved agencies have shared purposes and priorities (Drabble 2007). In her research on collaborative practice between the fields of child welfare and substance abuse treatment, Drabble identified that "the near unanimous consensus about the importance of addressing both substance abuse and child welfare issues may be a pivotal starting point for growing collaborative efforts, particularly if collaborating partners translate these values into formal policies and programs" (p. 38). Her study findings also point to the need for effective interagency communication related to case planning, values clarification and shared treatment principles, and involvement of community representatives in planning collaborative practices.

The four central agencies identified in our network analysis, along with the support of other substance abuse-related networks identified in a Canadian Centre on Substance Abuse report (Yip et al. 2010), could play significant leadership roles in consensus-building exercises to build the foundation for coordinated and integrated programs among a wider range of agencies nationwide to better serve women with substance abuse issues and their children. At the same time, consideration should be given to strategies to promote favourable conditions for collaboration given the importance of positive relationship qualities in predicting interagency activities. The creation of informal connections through the development of networks and joint events could foster relationship building and, ultimately, service integration.

The relevance of social capital can be extended to its role in the enhancement of knowledge exchange and the translation of knowledge to guide practice innovations (Scott and Hofmeyer 2007). Network structures and processes could be created to facilitate the sharing of information and to address the research-practice gap that characterizes the addiction treatment field (Damschroder and Hagedorn 2011; Garner 2009; Miller et al. 2006; Roman et al. 2010). Service providers and administrators in this field generally support the use of research findings in practice (Forman et al. 2001; Jack et al. 2011) yet, as suggested by our findings, they rarely are linked with academic researchers. Because agency partnerships with universities can promote evidence-informed practice (Dulmus and Cristalli 2012), it is important to further develop and build upon established linkages between agencies offering addiction services and universities in efforts to improve services for women with substance abuse issues and their children. Increased agency-university partnerships could both advance evidence-informed practice and enhance the clinical relevance of research efforts.

In addition to furthering such partnerships, specific attention needs to be paid to identifying and implementing strategies that are effective in promoting the adoption and 
implementation of research findings. It has been suggested that interactive engagement between researchers and clinical audiences in which equal importance is given to what each constituent group can learn from the other is essential to create a "cultural shift" to facilitate the ongoing use of empirically-derived knowledge (Lavis et al. 2003). These interactive efforts can be augmented with supporting infrastructures such as web sites and newsletters to further support knowledge translation (Lavis et al.). In addition, there is a need to provide training to clinicians to develop the skills and capacity for evidence-informed decision making, as well as to promote an organizational culture conducive to evidence-informed decision making (Dobbins et al. 2009). At the individual clinician level, monitored practice with feedback and expert coaching with positive reinforcement for improving practice are necessary to promote evidence-informed changes in approaches to care (Miller et al. 2006).

This study is the first of its kind to examine networks among agencies in Canada that serve women who abuse substances. It provided insight into existing linkages and direction for further development and expansion of collaborative agency partnerships. However, the study is not without its limitations. Most notably, the fact that a relatively small proportion of agencies approached to participate in the study were represented in the survey data suggests a potential for respondent bias. Caution therefore is warranted in generalizing the findings beyond the study sample. We relied on self-report of only program managers who may have identified community partners different than those that might have been identified by clinicians and executive directors in their agencies. Also, we limited the number of community partners that each program manager could list to keep the amount of data available for analysis manageable. Another study limitation that contributed to an incompletely described social network structure is the lack of data on the partnership patterns and activities of agencies identified as partners but that were not included in the survey. Finally, the regression model assumed that the partners were all independent and different, which is not exactly the case but given the large number of partners in comparison to the number of respondents ( $>950$ vs. 222), this assumption could be considered reasonable.

Future research could focus on the agencies identified as partners by addiction treatment agencies in our survey and examine the patterns, activities, and qualities of their partnerships with other agencies serving women with addictions and their children. Studies also could explore the barriers and facilitators at multiple levels to interagency partnerships, including partnerships between addiction treatment agencies and social agencies, prenatal/postnatal care, and child-focused agencies. While there may be common barriers and facilitators regardless of the agency type, there also are likely to be barriers and facilitators unique to the agencies of interest that are important to guide strategies to improve interagency collaboration. Another area of exploration for future research is partnerships between service agencies and universities. In particular, research is needed to explore the processes by which such partnerships can be established and sustained (Hart et al. 2009).

\section{Conclusions}

Partnerships exist between a number of agencies in Canada that provide services to women with substance abuse issues and their children. However, the extent and characteristics of these partnerships vary. All of the identified partnerships reflect within-province linkages, suggesting the need to expand connections across Canada. Four agencies played key linkage roles. Efforts should be made to build on the social capital inherent in these agencies to strengthen existing networks and to further develop networks among addiction agencies not only to improve services but also to enhance knowledge translation and exchange. There is a need for increased collaboration among community agencies to effectively meet the needs of 
women with substance abuse issues and their children. In particular, services delivery should ensure linkages between addiction treatment and social agencies that have a vital role in attending to the social determinants of health, thereby promoting the well-being of women and children. Additionally, further development of partnerships with prenatal/postnatal and child-focused agencies could help foster children's healthy growth and development. The four central agencies could be engaged in playing a significant role in promoting evidenceinformed practices as their status suggests they would be credible messengers and they have the potential to impact a wide range of agencies.

Acknowledgments This study was funded by the Canadian Institutes of Health Research TMF - 88574

Open Access This article is distributed under the terms of the Creative Commons Attribution License which permits any use, distribution, and reproduction in any medium, provided the original author(s) and the source are credited.

\section{References}

Bastian, M., Heymann, S., \& Jacomy, M. (2009). Gephi: An open source software for exploring and manipulating networks. International AAAI Conference on Weblogs and Social Media. Retrieved from https://gephi.org/users/publications/

Center for Substance Abuse Treatment. (2009). Substance abuse treatment: Addressing the specific needs of women. Treatment improvement protocol (TIP) Series 51. HHS Publication No. (SMA) 09-4426. Rockville, MD: Substance Abuse and Mental Health Services Administration.

Chisolm, M. S., \& Coleman-Cowger, V. H. (2011). Response: how to use a window of opportunity. Addiction Science \& Clinical Practice, 6, 71-72.

Conners, N. A., Bradley, R. H., Mansell, L. W., Liu, J. Y., Roberts, T. J., Burgdorf, K., et al. (2004). Children of mothers with serious substance abuse problems: an accumulation of risks. The American Journal of Drug and Alcohol Abuse, 30, 85-100.

Damschroder, L. J., \& Hagedorn, H. J. (2011). A guiding framework and approach for implementation research in substance use disorders treatment. Psychology of Addictive Behaviors, 25, 194-205.

Dobbins, M., Hanna, S., Ciliska, D., Manske, S., Cameron, R., Mercer, S., O’Mara, L., DeCorby, K., \& Robeson, P. (2009). A randomized controlled trial evaluating the impact of knowledge translation and exchange strategies. Implementation Science, 4:61. Retrieved from http://www.implementationscience.com/ content $/ 4 / 1 / 61$

Drabble, L. (2007). Pathways to collaboration: exploring values and collaborative practice between child welfare and substance abuse treatment fields. Child Maltreatment, 12, 31-42.

Dulmus, C. N., \& Cristalli, M. E. (2012). A university-community partnership to advance research in practice settings: the HUB research model. Research on Social Work Practice, 22, 195-202.

Dunn, M. G., Tarter, R. E., Mezzich, A. C., Vanyukov, M., Kirisci, L., \& Kirillova, G. (2002). Origins and consequences of child neglect in substance abuse families. Clinical Psychology Review, 22, 1063-1090.

Epstein, J., Barker, P., Vorburger, M., \& Murtha, C. (2004). Serious mental illness and its co-occurrence with substance use disorders, 2002. (DHHS Publication No. SMA 04-3905, Analytic Series A-24). Rockville, MD: Substance Abuse and Mental Health Services Administration, Office of Applied Study.

Forman, R. F., Bovasso, G., \& Woody, G. (2001). Staff beliefs about addiction treatment. Journal of Substance Abuse Treatment, 21, 1-9.

Garner, B. R. (2009). Research on the diffusion of evidence-based treatments within substance abuse treatment: a systematic review. Journal of Substance Abuse Treatment, 36, 376-399.

Goel, N., Beasley, D., Rajkumar, V., \& Banerjee, S. (2011). Perinatal outcomes of illicit substance use in pregnancy-comparative and contemporary socio-clinical profile in the UK. European Journal of Pediatrics, 170, 199-205.

Greenhalgh, T., Robert, G., Macfarlane, F., Bate, P., \& Kyriakidou, O. (2004). Diffusion of innovations in service organizations: systematic review and recommendations. The Milbank Quarterly, 82, 581-629.

Hart, A., Northmore, S., Gerhardt, C., \& Rodriquez, P. (2009). Developing access between universities and local community groups: a university helpdesk in action. Journal of Higher Education Outreach and Engagement, 13, 45-59. 
Health Canada. (2012). Drug prevention and treatment. Retrieved from http://www.hc-sc.gc.ca/hc-ps/drugsdrogues/index-eng.php

Hjerkinn, B., Lindbæk, M., \& Rosvold, E. O. (2007). Substance abuse in pregnant women. Experiences from a special child welfare clinic in Norway. BMC Public Health, 7, 322.

Howell, E. M., \& Chasnoff, I. J. (1999). Perinatal substance abuse treatment. Findings from focus groups with clients and providers. Journal of Substance Abuse Treatment, 17, 139-148.

Jack, S. M., Dobbins, M., Sword, W., Novotna, G., Brooks, S., Lipman, E. L., et al. (2011). Evidenceinformed decision-making by professionals working in addiction agencies serving women: a descriptive qualitative study. Substance Abuse Treatment, Prevention, and Policy, 6, 29.

Kelley, S. J. (1998). Stress and coping behaviors of substance-abusing mothers. Journal of the Society of Pediatric Nursing, 3, 103-110.

Kuczkowski, K. M. (2007). The effects of drug abuse on pregnancy. Current Opinion in Obstetrics \& Gynecology, 19, 578-585.

Lavis, J. N., Robertson, D., Woodside, J. M., Mcleod, C. B., \& Abelson, J. (2003). How can research organizations more effectively transfer research knowledge to decision makers? The Milbank Quarterly, $81,221-248$.

Mayes, L. C., \& Truman, S. D. (2002). Substance abuse and parenting. In M. H. Bornstein (Ed.), Handbook of parenting: Vol. 4. Applied parenting (2nd ed., pp. 329-360). Mahwah: Lawrence Erlbaum Associates.

Miller, W. R., Sorensen, J. L., Selzer, J. A., \& Brigham, G. S. (2006). Disseminating evidence-based practices in substance abuse treatment: a review with suggestions. Journal of Substance Abuse Treatment, 31, 25-39.

Milligan, K., Niccols, A., Sword, W., Thabane, L., Henderson, J., Smith, A., et al. (2010). Maternal substance use and integrated treatment programs for women with substance abuse issues and their children: a metaanalysis. Substance Abuse Treatment, Prevention, and Policy, 5, 21.

Milligan, K., Niccols, A., Sword, W., Thabane, L., Henderson, J., \& Smith, A. (2011). Birth outcomes for infants born to women participating in integrated substance abuse treatment programs: a meta-analytic review. Addiction Research and Theory, 19, 542-555.

Nahapiet, J., \& Ghoshal, S. (1998). Social capital, intellectual capital, and the organizational advantage. Academy of Management Review, 23, 242-267.

National Treatment Strategy Working Group. (2008). A systems approach to substance use in Canada. Recommendations for a national treatment strategy. Ottawa: National Framework for Action to Reduce the Harms Associated with Alcohol and Other Drugs and Substances in Canada. Retrieved from http:// www.nts-snt.ca/2010\%20Documents/nts-report-eng.pdf

Niccols, A., Milligan, K., Sword, W., Thabane, L., Henderson, J., Smith, A., et al. (2010). Maternal mental health and integrated programs for mothers with substance abuse issues. Psychology of Addictive Behaviors, 24, 466-474.

Niccols, A., Milligan, K., Sword, W., Thabance, L., Henderson, J., \& Smith, A. (2012). Integrated programs for mothers with substance abuse issues: a systematic review of studies reporting on parenting outcomes. Harm Reduction Journal, 9, 14. doi:10.1186/1477-7517-9-14.

Palinkas, L. A., Holloway, I. W., Rice, E., Fuentes, D., Wu, Q., \& Chamberlain, P. (2011). Social networks and implementation of evidence-based practices in public youth-serving systems: a mixed-methods study. Implementation Science, 6, 113. doi:10.1186/1748-5908-6-113.

Poole, N., \& Dell, C.A. (2005). Girls, women and substance use. Ottawa, ON: Canadian Centre on Substance Abuse. Retrieved from www.ccsa.ca/2005\%20CCSA\%20Documents/ccsa-011142-2005.pdf

Poole, N., \& Urquhart, C. (2009). Trauma-informed approaches in addictions treatment, Gendering the National Framework Series (Vol. 1). Vancouver, BC: British Columbia Centre of Excellence for Women's Health. Retrieved from www.bccewh.bc.ca/.../GenderingNatFrameworkTraumaInformed.pdf

Poole, N., \& Urquhart, C. (2010). Mothering and substance use: Approaches to prevention, harm reduction and treatment, Gendering the National Framework Series (Vol. 3). Vancouver, BC: British Columbia Centre of Excellence for Women's Health. Retrieved from www.bccewh.bc.ca/.../ GenderingNatFrameworkMotheringandSubstanceUse.pdf

Provan, K. G., Veazie, M. A., Staten, L. K., \& Teufel-Shone, N. I. (2005). The use of network analysis to strengthen community partnerships. Public Administration Review, 65, 603-613.

Roberts, S. C., \& Pies, C. (2011). Complex calculations: how drug use during pregnancy becomes a barrier to prenatal care. Maternal and Child Health Journal, 15, 333-341.

Rogers, E. (2003). Diffusion of innovations (5th ed.). New York: Free Press.

Roman, P. M., Abraham, A. J., Rothrauff, T. C., \& Knudsen, H. K. (2010). A longitudinal study of organizational formation, innovation adoption, and dissemination activities within the National Drug Abuse Treatment Clinical Trials Network. Journal of Substance Abuse Treatment, 38(Suppl 1), S44-S52.

Schempf, A. H. (2007). Illicit drug use and neonatal outcomes: a critical review. Obstetrical \& Gynecological Survey, 62, 749-757. 
Scott, C., \& Hofmeyer, C. (2007). Networks and social capital: a relational approach to primary healthcare reform. Health Research Policy and Systems, 5, 9.

Suchman, N. E., \& Luthar, S. S. (2000). Maternal addiction, child maladjustment and socio-demographic risks: implications for parenting behaviors. Addiction, 95, 1417-1428.

Sword, W., Jack, S., Niccols, A., Milligan, K., Henderson, J., \& Thabane, L. (2009). Integrated programs for women with substance use issues and their children: a qualitative meta-synthesis of processes and outcomes. Harm Reduction Journal, 6, 32.

United Nations Office on Drugs and Crime. (2004). Substance abuse treatment and care for women: Case studies and lessons learned. Drug Abuse Treatment Toolkit. Vienna: UNODC. Retrieved from www.unodc.org/docs/treatment/Case_Studies_E.pdf

Walsh, C., MacMillan, H. L., \& Jamieson, E. (2003). The relationship between parental substance abuse and child maltreatment: findings from the Ontario Health Supplement. Child Abuse \& Neglect, 27, 14091425 .

Yip, A., Bullock, H., \& Butterill, D. (2010). Substance abuse knowledge exchange networks: An environmental scan. Canadian Centre on Substance Abuse. Retrieved from http://www.nts-snt.ca/ 2010\%20Documents/2011_NTS_KE_Environmental_Scan_Report_en.pdf 